\title{
Pathogenicity of Phyllosticta citricarpa Ascospores on Citrus spp.
}

Nga T. Tran, ${ }^{\dagger}$ Centre for Horticultural Science (CHS), Queensland Alliance for Agriculture and Food Innovation (QAAFI), The University of Queensland, Ecosciences Precinct, Dutton Park, QLD 4102, Australia; and School of Agriculture and Forestry, Hue University, Vietnam; Andrew K. Miles, CHS, QAAFI, The University of Queensland, Ecosciences Precinct; Malcolm W. Smith, Queensland Department of Agriculture and Fisheries, Bundaberg Research Station, QLD 4670, Australia; Ralf G. Dietzgen, CHS, QAAFI, The University of Queensland, Queensland Bioscience Precinct, St. Lucia, QLD 4072, Australia; and André Drenth, CHS, QAAFI, The University of Queensland, Ecosciences Precinct

\begin{abstract}
Citrus black spot, caused by Phyllosticta citricarpa, is one of the most important fungal diseases in many citrus-growing regions with hot and humid summers. Ascospores and conidia are known to contribute to epidemic development of the disease. However, pathogenicity testing has never been done for pure ascospores produced from fully characterized $P$. citricarpa isolates, due to the inability to induce the sexual state in vitro. Recently, an in vitro mating technique was developed to readily produce pure $P$. citricarpa ascospores for use in host inoculation studies. To test the pathogenicity of $P$. citricarpa ascospores, we inoculated Troyer citrange leaves and Murcott tangor fruit with ascospores produced in vitro from characterized $P$. citricarpa isolates. Typical symptoms of citrus black spot occurred. Recovery

of $P$. citricarpa isolates from symptomatic lesions and their characterization using genetic markers enabled us to identify recombinant genotypes among the isolates recovered from ascospore inoculations and, as such, fulfill Koch's postulates for ascospores. We have also identified Troyer citrange seedlings as a potential model system for citrus black spot inoculation studies, because it allows typical symptoms of citrus black spot to be expressed with a much shorter latent period than on fruit. This will facilitate future studies of epidemiological aspects of $P$. citricarpa ascospores relative to conidia and improve our understanding of the citrus black spot pathosystem. The susceptibility of Troyer citrange seedlings will also facilitate experimenting with disease management methods, aimed at reducing the impact of citrus black spot.
\end{abstract}

Citrus black spot, caused by the fungus Phyllosticta citricarpa McAlpine (synonym: Guignardia citricarpa Kiely), is one of the most important fungal diseases in citrus-producing areas with warm temperatures and summer rainfall, including parts of Australia, Asia, Africa, South America, and North America (Brentu et al. 2012; Kotzé 1981; Schubert et al. 2012; Yonow et al. 2013). Most recently, P. citricarpa has been reported in Europe although citrus black spot symptoms have never been observed (Guarnaccia et al. 2017). Almost all cultivated Citrus spp. are known to be susceptible to the disease (Baldassari et al. 2008; Kotzé 1981). Fruit can be infected by P. citricarpa any time from fruit set up to 6 months later, after which the pathogen remains latent for another 4 to 6 months until fruit are mature and visible symptoms start to appear (Baldassari et al. 2006; Kiely 1948; Kotzé 1981). There are various types of symptoms associated with citrus black spot, including hard spot, freckle spot, virulent spot, false melanose, and cracked spot (de Goes et al. 2000; Kiely 1948; Kotzé 1981). The classic hard spot symptom type is characterized by sunken lesions with dark margins and typically a light tan to gray center, often containing pycnidia (Kiely 1948; Schubert et al. 2012). Freckle spot is also a common symptom type, and is described as a small red depressed lesion which sometimes contains pycnidia (Brentu et al. 2012; de Goes et al. 2000). Leaf and twig symptoms are rare but can sometimes be observed on highly susceptible Citrus spp. such as Citrus limon L. or on stressed trees (Brentu et al. 2012; Kotzé 1981). The citrus black spot lesions lead to reduced value of fresh fruit, and substantial direct yield

\section{${ }^{\dagger}$ Corresponding author: N. T. Tran; E-mail: nga.tran1@uq.net.au}

Funding: This research was jointly supported by the Queensland Department of Agriculture and Fisheries and the University of Queensland through the Queensland Alliance for Agriculture and Food Innovation. N. T. Tran was sponsored by University of Queensland through an Ernest Singer Ph.D. stipend and Top-Up scholarships and UQI tuition fee scholarship. Funds have also been provided by the Citrus Research and Development Foundation (grant number 715) through the University of Florida and Horticulture Innovation Australia.

Accepted for publication 2 February 2018.

() 2018 The American Phytopathological Society loss from premature drop of heavily infected fruit (Baldassari et al. 2008; Brentu et al. 2012).

$P$. citricarpa is heterothallic, with asexual reproduction producing conidia in pycnidia and sexual reproduction producing airborne ascospores in pseudothecia (Baldassari et al. 2008; Kotzé 1981; Tran et al. 2017). Under orchard conditions, conidia are readily formed on fruit lesions, dead twigs, and leaf litter (Kotzé 1981; Spósito et al. 2011), whereas ascospores are only known to be produced in leaf litter after two mating types undergo sexual reproduction (Carstens et al. 2017; Tran et al. 2017; Wang et al. 2016). Although both spore types can serve as a source of inoculum (Kotzé 1981; Spósito et al. 2011), their relative importance in disease epidemiology is unknown. Several studies have reported that ascospores play the most important role and are the primary source of inoculum, being wind dispersed over longer distances compared with the short-distance dispersal of conidia via rain splash (Fourie et al. 2013; Kiely 1948; Kotzé 1981; McOnie 1964b,a). Conversely, other studies consider conidia to be more important, particularly in areas with frequent summer rains or where there is an overlap between mature diseased fruit and young susceptible fruit present in the tree canopy (Carstens et al. 2017; Spósito et al. 2011; Wang et al. 2016). Thus, existing studies on the relative importance of conidia and ascospores have been mainly concerned with the nature of their dispersal, although knowledge is still limited on other epidemiological aspects such as pathogenicity, viability, and fecundity of both spore types. In order to better understand the epidemiological roles of $P$. citricarpa ascospores and conidia, experimentation to directly compare various epidemiological aspects of the two spore types is required.

Although the role of ascospores in the epidemiology of citrus black spot is postulated, studies of their spread, ability to infect and colonize plant tissue, cause disease, and sporulate have been hampered by the inability to induce the sexual state of $P$. citricarpa in vitro (Amorim et al. 2017; Baayen et al. 2002; Baldassari et al. 2008; Kotzé 1981; Spósito et al. 2008; Wang et al. 2016). Past studies aiming to investigate the epidemiological roles of $P$. citricarpa ascospores, including their pathogenicity, relied on collecting ascospores from naturally infected field material (McOnie 1964a, 1967) in the absence of precise knowledge about the inoculum identity and pathogenicity. Ascospores collected from field material may contain mixtures of $P$. citricarpa and other Phyllosticta spp. associated with Citrus, especially P. capitalensis (Glienke et al. 2011; Guarnaccia et al. 2017; Wang et al. 2012; Wikee 
et al. 2013; Wulandari et al. 2009). Of the Phyllosticta spp. other than $P$. citricarpa, the endophyte $P$. capitalensis is relatively well studied (Baayen et al. 2002; Glienke et al. 2011; Wikee et al. 2013). $P$. capitalensis is homothallic, readily produces ascospores in vitro and in leaf litter, is widespread, and often coexists with $P$. citricarpa in orchards (Baayen et al. 2002; Wang et al. 2016). McOnie (1964a) conducted pathogenicity tests for ascospores by placing naturally infected dead leaves covered with pseudothecia and pycnidia on attached grapefruit. Although citrus black spot symptoms were produced from this study, it could not be concluded that ascospores were responsible for the symptoms because conidia, which commonly infect citrus fruit and cause symptoms, were also present in the inoculum. Moreover, pseudothecia found on the infected leaves could have been derived from the endophyte $P$. capitalensis because no species identification was reported. Baldassari et al. (2008) confirmed the pathogenicity of $P$. citricarpa isolates grown from ascospores captured from citrus leaf litter but pathogenicity tests were done using conidia derived from those ascospore cultures rather than using ascospores themselves, leaving the pathogenicity and role of ascospores in disease epidemiology unconfirmed. Recently, we developed an in vitro mating technique for $P$. citricarpa that enabled efficient production of pseudothecia as well as the release and collection of relatively large numbers of ascospores (Tran et al. 2017). This technique allows pathogenicity tests and studies of other epidemiological aspects, including their germination, infection, and viability, to be undertaken using ascospores produced from fully characterized $P$. citricarpa isolates.

The long latent period of citrus black spot, generally 4 to 6 months before symptoms are expressed on fruit (Kiely 1948; Kotzé 1981), restricts the usefulness of detached fruit assays (Marques et al. 2011), and studies using attached fruit also face many challenges. For example, Moran Lemir et al. (2000) produced citrus black spot symptoms on lemon, the most susceptible citrus species, 6 months after inoculation. In another inoculation study, only false melanose and freckle spot were found on Pera-Rio sweet orange and it took 5 months from inoculation for the symptoms to become evident (Baldassari et al. 2009). Another challenge of inoculating attached fruit is that it can only be performed within a very restricted period of time because most citrus cultivars produce only one crop each season (Iglesias et al. 2007). Although the use of controlled-environment cabinets may overcome the seasonality of citrus fruit production to some degree, such facilities are generally not ideal for housing mature citrus trees with fruit that are typically quite large in size (Wheaton et al. 1991). Therefore, in order to facilitate further studies, it will be necessary to identify an experimental model species on which disease symptoms can be expressed more rapidly. In preliminary experiments involving spraying $P$. citricarpa conidial suspensions onto the leaves of seedlings of Troyer citrange (C. sinensis $\times$ Poncirus trifoliata), which is an important and commonly used citrus rootstock (Castle 2010), we observed Troyer seedlings to be susceptible to $P$. citricarpa and produced typical hard spot symptoms on leaves only 2 months after inoculation. The apparent susceptibility of young Troyer seedlings to $P$. citricarpa, would be a significant aid to conducting inoculation studies of citrus black spot.

The overall aim of this study was to investigate the role that ascospores play in the epidemiology of citrus black spot. The specific objectives were to test whether (i) ascospores of $P$. citricarpa produced in vitro are pathogenic on Citrus spp., (ii) leaf and fruit infections are caused by hybrid ascospores resulting from the two parental isolates used to produce the ascospores in vitro, and (iii) Troyer seedlings are susceptible to $P$. citricarpa and readily produce foliar citrus black spot symptoms. An improved understanding of the role of ascospores in the disease cycle may facilitate more detailed investigations of $P$. citricarpa infection biology and epidemiology, leading to more targeted management of citrus black spot.

\section{Materials and Methods}

Fungal isolates. $P$. citricarpa isolate BRIP 53711 (MAT1-1 idiomorph), the ex-epitype isolate BRIP 52614 (= CBS 127454; MAT12 idiomorph) (Glienke et al. 2011; Guarnaccia et al. 2017), and BRIP 54232 (MAT1-2 idiomorph), retrieved from the Queensland Plant
Pathology Herbarium (BRIP), were used for the inoculation assays. These three isolates were previously characterized by sequence analysis of the internal transcribed spacer region and partial translation elongation factor 1- $\alpha$ gene (Miles et al. 2013). They had been screened for mating types by polymerase chain reaction (PCR) with specific primers and shown to be unique genotypes through multilocus genotyping (Tran et al. 2017; Wang et al. 2016). The isolates were also found to readily produce ascospores when crossed with the other isolates of complementary idiomorph (Tran et al. 2017). The three isolates were cultured on half-strength potato dextrose agar (1/2 PDA) at room temperature for 2 weeks prior to inoculum preparation.

Inoculum preparation. Ascospores were produced from two crosses (BRIP $53711 \times 52614$ and BRIP $53711 \times 54232$ ) using the "sandwich mating" technique described by Tran et al. (2017), with some modifications. Two-week-old cultures of isolate BRIP 53711 grown on 1/2 PDA were flooded with sterile distilled water before using a glass spreader to gently scrape the colony to induce the release of spores. The resulting spore suspension that contained conidia and spermatia was then used to fertilize isolates of the complementary MAT idiomorph (BRIP 52614 and 54232) by pipetting the suspension to fully cover colonies of the other isolate. The plates were then kept at ambient conditions on a laboratory bench. Approximately 2 weeks after fertilization, when the fertilizing spore suspensions had air dried and ascospore release began, the Petri dish lid was replaced with a new sterile lid to capture $P$. citricarpa ascospores. As soon as ascospores were found abundantly on the Petri dish lid, 1 to $2 \mathrm{ml}$ of $0.02 \%$ (vol/vol) Tween 20 (Sigma-Aldrich, Castle Hill, NSW, Australia) was added to the area with ascospores, and the spores were dislodged with a soft brush. Ascospore suspensions were transferred to sterile centrifuge tubes, and the concentration was determined using a hemocytometer and adjusted as required.

Conidia suspensions of the three parental isolates (BRIP 53711, 52614, and 54232) for use in the leaf inoculation experiments were prepared by flooding 2-week-old cultures with $0.02 \%$ Tween 20 and incubating for $30 \mathrm{~min}$ to allow spore release. The resulting suspensions were transferred to sterile centrifuge tubes, and the spore concentration was determined and standardized. Based on P. citricarpa conidia concentrations $\left(10^{4}\right.$ to $10^{5}$ spores $\left./ \mathrm{ml}\right)$ used in the literature (Moran Lemir et al. 2000; Truter et al. 2007) and spore availability at each inoculation experiment in the present study, the working concentrations of ascospores and conidia were $5 \times 10^{3}$ to $1 \times 10^{5}$ spores $/ \mathrm{ml}$.

Plant materials. To determine whether Troyer seedlings express citrus black spot symptoms on young leaves, seed of Troyer were sown in pasteurized potting mix (75\% composted pine bark and $25 \%$ 4-mm stone [ $\mathrm{vol} / \mathrm{vol}], \mathrm{pH} 5.5$, air-filled porosity $22 \%$ ), placed in a shadehouse $\left(20\right.$ to $\left.35^{\circ} \mathrm{C}\right)$, and fertigated every 2 weeks. Approximately 1 month before commencement of the inoculation experiments, the 1-year-old seedlings were potted in polypropylene pots (135 by 140 by $135 \mathrm{~mm}$ ) containing University of California soilless mix (Baker 1957). To stimulate new growth, potted seedlings were kept in a growth cabinet at 28 and $25^{\circ} \mathrm{C}$ day and night, respectively; with $12 \mathrm{~h}$ of light, $12 \mathrm{~h}$ of darkness, and $90 \%$ relative humidity; and watered every 2 days until adequate new flush was available for inoculation.

To test the ability of ascospores to cause disease on citrus fruit, potted 3-year-old Murcott tangor $(C$. reticulata $\times C$. sinensis) trees were obtained from a commercial nursery and maintained in an isolated shadehouse to produce fruit free of background citrus black spot infection. Approximately 3-month-old fruit were used for inoculation.

Pathogenicity studies. Leaf inoculation. Prior to inoculation, Troyer seedlings with soft new growth were watered and then moved to a controlled-environment cabinet at $25^{\circ} \mathrm{C}$ and $95 \%$ relative humidity in darkness. Ascospores of each cross (BRIP $53711 \times 52614$ and BRIP $53711 \times 54232$ ), conidia of each of three parental isolates, and $0.02 \%$ Tween 20 as a negative control were used for inoculation. Leaves were inoculated by placing 10 drops of a $5-\mu 1$ spore suspension or $0.02 \%$ Tween 20 on each leaf. Two separate inoculation experiments were performed with the spore concentrations of $1 \times 10^{5}$ spores $/ \mathrm{ml}$ (experiment 1 ) and $5 \times 10^{4}$ spores $/ \mathrm{ml}$ (experiment 2). For each experiment, there were three replicate Troyer seedlings per treatment. On each seedling, all available half-expanded soft leaves, fully expanded soft leaves, 
and two fully mature leaves were inoculated. Inoculated seedlings remained in the controlled-environment cabinet for $96 \mathrm{~h}$ before transfer to a glasshouse at approximately $25^{\circ} \mathrm{C}$.

Fruit inoculation. Tests were conducted under shadehouse conditions on Murcott fruit. Ascospores produced in vitro from the cross BRIP $53711 \times 54232$ at a concentration of $5 \times 10^{3}$ spores $/ \mathrm{ml}$, and $0.02 \%$ Tween 20 as a negative control, were used. Four replicate fruit (approximately 3 months old) per treatment were inoculated using a blotting paper strip technique outlined by Miles et al. (2016). Briefly, fruit were first misted with sterile water before a 5-mm-wide strip of sterile blotting paper was soaked in spore suspension or $0.02 \%$ Tween 20, then wrapped around the entire equator of the fruit. The blotting paper was then covered with a strip of domestic cling wrap to maintain high moisture conditions. Finally, the entire fruit was wrapped in aluminum foil to minimize sun exposure and heat. After $48 \mathrm{~h}$, the foil, cling wrap, and blotting paper were all removed. Fruit were left to mature on the tree for as long as possible and covered with a mesh bag prior to harvest to reduce the risk of losing fruit. After harvest, fruit were incubated at constant light, $27^{\circ} \mathrm{C}$, and $80 \%$ relative humidity for 3 weeks before assessment of disease expression (Brodrick 1970).

Disease assessment and statistical analyses. For leaf inoculation assays, disease incidence was assessed by recording binominal data of leaves with or without symptoms and severity was assessed by counting the number of lesions on each inoculated leaf at 4 months after inoculation. Disease incidence and severity for inoculum source (combined across all leaf developmental stages) and for leaf developmental stage (combined across all inoculum sources) in each inoculation experiment were analyzed separately using GenStat (16th edition; VSN International Ltd., Hemel Hempstead, HP2 4TP, UK). A generalized linear model with a binomial distribution and logit link was applied to the binomial incidence data while severity data were subjected to unbalanced analysis of variance due to the unequal number of leaves inoculated for each treatment, to compare the relative aggressiveness of different spore treatments. Replicates were included as a blocking factor and inoculum source, leaf developmental stage, and their interaction were included as treatment factors. Any nonsignificant $(P>0.05)$ interactions were dropped from the model. To test the relationships between means, pairwise comparisons were performed for all significant analyses $(P<0.05)$ using Fisher's least significant difference test. For the fruit inoculation experiment, spore-inoculated fruit were recorded as disease symptoms present or absent.

Reisolation, identification, and single spore isolation. In order to fulfill Koch's postulates concerning the ability of ascospores to cause disease and produce spores on infected plant materials, reisolation was done as follows. Inoculated leaves and fruit were surface sterilized by swabbing with $70 \%$ ethanol. Tissues of single lesions from spore treatments, as well as asymptomatic tissues from $0.02 \%$ Tween 20 treatments, were plated onto 1/2 PDA. Once a Phyllosticta colony grew, it was subcultured onto a new 1/2 PDA plate. After about 2 weeks, monoconidial isolates were generated by gently pipetting $1 \mathrm{ml}$ of sterile water onto the colonies and incubating for about $10 \mathrm{~min}$ to allow spore release. The resulting spore suspension $(10 \mu \mathrm{l})$ was then spread over a new 1/2 PDA plate. Daily examination of the plates allowed single germinating conidia to be transferred to a fresh 1/2 PDA plate to obtain monoconidial isolates for identification and DNA extraction. Monoconidial isolates were identified as $P$. citricarpa based on the morphology of colonies and spores grown on $1 / 2$ PDA, and the presence of a yellow halo around colonies grown on oatmeal agar (Baayen et al. 2002; Baldassari et al. 2008).

Multilocus genotyping. Multilocus genotyping was used to examine genetic recombination and, thus, determine whether $P$. citricarpa isolates recovered from symptomatic tissue following ascospore inoculation were associated with isolates of recombinant genotypes, resulting from sexual reproduction.

DNA isolation. DNA was extracted from monoconidial isolates of $P$. citricarpa grown on $1 / 2$ PDA. After scraping fungal mycelia and spores from culture plates, total genomic DNA (gDNA) was extracted using the Wizard Genomic DNA purification kit (Promega Corp., Madison WI), following the manufacturer's instructions.
DNA concentrations were determined using a DUO spectrophotometer (BioDrop, Cambridge, UK) and diluted using Milli-Q water to a final concentration of 15 to $30 \mathrm{ng} / \mu \mathrm{l}$ prior to genotyping.

Genotyping. P. citricarpa isolates recovered from inoculation with ascospores of the cross BRIP $53711 \times 54232$ and their corresponding conidia inoculations were genotyped. Previously, Tran et al. (2017) demonstrated polymorphisms among progeny of this same cross (BRIP $53711 \times 54232$ ) using two simple sequence repeat (SSR) loci 6 and 12 and the mating type locus of Wang et al. (2016). In addition to these three loci, SSR locus Pc117 developed by Carstens et al. (2017) was included in the genotyping. Parental isolates BRIP 53711 and 54232 retrieved from the Queensland Plant Pathology Herbarium were included as known standards.

PCR amplifications of the SSR loci 6 and 12 and Pc117 using published primer pairs $6 \mathrm{~F}$ and $6 \mathrm{R}, 12 \mathrm{~F}$ and $12 \mathrm{R}$ (Wang et al. 2016), and Pc117F and Pc117R (Carstens et al. 2017), respectively, were performed in $20-\mu 1$ reactions, each containing approximately $20 \mathrm{ng}$ of gDNA (Qiagen nuclease-free water served as a no-template control), $4.0 \mu \mathrm{l}$ of $5 \times$ MyTaq Red reaction buffer (Bioline), $0.2 \mu \mathrm{l}$ each of $10 \mu \mathrm{M}$ primer, and $0.2 \mu \mathrm{l}$ of MyTaq HS DNA polymerase at $5 \mathrm{U} / \mu \mathrm{l}$ (Bioline). The following cycling conditions were used: $1 \mathrm{~min}$ at $94^{\circ} \mathrm{C} ; 35$ cycles of $94^{\circ} \mathrm{C}$ for $20 \mathrm{~s}, 58^{\circ} \mathrm{C}$ for $20 \mathrm{~s}$, and $72^{\circ} \mathrm{C}$ for $20 \mathrm{~s}$; followed by a final extension of $72^{\circ} \mathrm{C}$ for $2 \mathrm{~min}$. PCR products were size fractionated on $1.5 \%$ agarose gels to examine DNA quality and size. PCR products were directly sequenced, using the same primers as used for PCR amplifications, by Macrogen Incorporated using an AB 3730xl DNA Analyzer (Applied Biosystems, Foster City, CA) to determine the number of repeat motifs of each SSR locus.

PCR amplifications of the mating type locus using primer pairs Gcmat1-56f and Gcmat1-686r specific to MAT1-1 and Gcmat2686f and Gcmat2-1185r specific to MAT1-2 (Wang et al. 2016) were performed in $10-\mu 1$ reactions, each containing approximately $20 \mathrm{ng}$ of gDNA (Qiagen nuclease-free water served as a no-template control), $2.0 \mu \mathrm{l}$ of $5 \times$ MyTaq Red reaction buffer (Bioline), $0.1 \mu \mathrm{l}$ each of $10 \mu \mathrm{M}$ primer, and $0.1 \mu \mathrm{l}$ of MyTaq HS DNA polymerase at $5 \mathrm{U} / \mu \mathrm{l}$ (Bioline). Cycling conditions were as follows: $2 \mathrm{~min}$ at $95^{\circ} \mathrm{C} ; 35$ cycles of $95^{\circ} \mathrm{C}$ for $15 \mathrm{~s}, 59^{\circ} \mathrm{C}$ for $15 \mathrm{~s}$, and $72^{\circ} \mathrm{C}$ for 30 $\mathrm{s}$; followed by a final extension of $72^{\circ} \mathrm{C}$ for $2 \mathrm{~min}$. PCR products were size fractionated on $1.5 \%$ agarose gels to compare sizes of DNA fragments with those from the parental isolates BRIP 53711 and 54232 for MAT1-1 (630 bp) and MAT1-2 (500 bp), respectively.

\section{Results}

Pathogenicity of $\boldsymbol{P}$. citricarpa ascospores on Troyer leaves. Inoculation of Troyer leaves with ascospores produced in vitro from two crosses (BRIP $53711 \times 52614$ and BRIP $53711 \times 54232$ ) and conidia of the three parental isolates resulted in citrus black spot symptoms, including hard spot containing pycnidia and freckle spot (Fig. 1A and B). These symptoms were visible as small lesions (1 to $2 \mathrm{~mm}$ in diameter) at 65 days after inoculation and developed further with pycnidia observed after a further 20 days. No citrus black spot symptoms were observed in control plants (Fig. 1C). P. citricarpa isolates were recovered from all 99 citrus black spot lesions examined but never from the site of inoculation of 10 control leaves.

Results for experiment 1 showed that disease incidence for conidia of the isolate BRIP $53711(64.4 \%)$ and ascospores of the cross BRIP $53711 \times 54232(61.1 \%)$ were not significantly different from each other but significantly higher $(P<0.001)$ than the other spore treatments (Fig. $2 \mathrm{~A})$. The differences between disease incidence for conidia of the isolate BRIP 52614 (23.7\%) and isolate BRIP 54232 (30.0\%) were nonsignificant (Fig. 2A). Likewise, disease incidence for conidia of BRIP 54232 was not statistically different from that for ascospores of the cross BRIP $53711 \times 52614(42.6 \%)$ (Fig. 2A). Within each cross, disease incidence for the ascospores was in the range of those for conidia of the two parental isolates (Fig. 2A). In particular, ascospores of the cross BRIP $53711 \times 52614$ had a significantly lower $(P<0.001)$ disease incidence than conidia of the parental isolate BRIP 53711 but higher $(P<$ 0.001) than conidia of the other parental isolate BRIP 52614 (Fig. 2A). Ascospores of the cross BRIP $53711 \times 54232$ had a similar disease incidence to conidia of the parent BRIP 53711 but significantly higher 
than that for conidia of the other parent BRIP 54232 (Fig. 2A). Disease severity was near significant $(P=0.054)$ among the isolates and spore types, which ranged from 1.5 to 3.5 lesions/leaf (Fig. 2B).

In experiment 2 , disease incidence varied among conidia of different genotypes and ascospores of the two crosses (Fig. 2C). Disease incidence for conidia of the isolate BRIP 52614 (16\%) was not statistically different from that for ascospores of the cross BRIP $53711 \times$ $52614(29.8 \%)$ but was significantly lower $(P<0.001)$ than that for the other spore treatments, where disease incidence ranged from 35.2 to $39.0 \%$ (Fig. 2C). Within each cross, disease incidence for ascospores was also in the range of that for conidia of the two parents. Plants inoculated with conidia of BRIP 53711 had a significantly higher $(P<$ 0.001) disease incidence than that for conidia of BRIP 52614; however, these values were not significantly different from disease incidence for ascospores produced from these two parental isolates (BRIP $53711 \times$ 52614) (Fig. 2C). Disease incidence for ascospores of the cross BRIP $53711 \times 54232$ was not significantly different from that for the corresponding conidia of both parents (Fig. 2C). Disease severity was not significantly different $(P=0.120)$ between isolates and spore types, ranging from 0.3 to 2.0 lesions/leaf (Fig. 2D).

Comparing disease incidence and severity of the two experiments showed that the data were generally higher for experiment 1 , in which a higher inoculum concentration $\left(1 \times 10^{5}\right.$ spores $\left./ \mathrm{ml}\right)$ was used, than for experiment 2 , with the lower inoculum concentration $(5 \times$ $10^{4}$ spores/ml) (Fig. 2A to D).

Regarding leaf developmental stage, both experiments consistently showed that disease incidence and severity were significantly different $(P<0.001)$ between leaf developmental stages and highest for halfexpanded soft leaves. Disease incidence and severity for half-expanded soft leaves were 54.0 to $73.0 \%$ and 3.6 to 7.6 lesions/leaf, respectively (Fig. 3). Fully expanded soft and fully mature leaves had less than $30.0 \%$ disease incidence and less than 1.2 lesions/leaf for disease severity (Fig. 3). In addition, citrus black spot lesions observed on mature leaves were not as typical as those seen on the younger leaf types, because mature leaf lesions did not form pycnidia. Analysis of the interaction between inoculum source and leaf developmental stage showed a significant effect $(P=0.016)$ in disease incidence for experiment 2 , such that mature leaves were only infected by conidia of the isolates BRIP 53711 and 52614. However, there was no significant interaction for disease severity $(P=0.402)$ and, likewise, experiment 1 showed no significant interactions, with $P=0.468$ and 0.353 for disease incidence and severity, respectively. Data for individual factors in the two experiments are shown graphically in Figures 2 and 3.

Pathogenicity of $\boldsymbol{P}$. citricarpa ascospores on Murcott fruit. Citrus black spot symptoms developed on Murcott fruit 5 months after inoculation with ascospores of the cross BRIP $53711 \times 54232$ (Fig. 4). No symptoms were seen on control fruit. P. citricarpa was recovered from all four lesions examined but not from any of four inoculation points of control fruit.
Multilocus genotyping. Multilocus genotyping using three SSR loci and the mating type locus enabled confirmation of the clonal nature of $P$. citricarpa isolates recovered from conidia inoculation, and identification of recombinant genotypes in the $P$. citricarpa isolates recovered from ascospore inoculation of Troyer leaves and Murcott fruit (Table 1). As expected, $100 \%$ of $P$. citricarpa isolates recovered from citrus black spot symptoms that arose from inoculation with conidia of isolates BRIP 53711 and 54232 were of the parental genotypes. In contrast, $84 \%$ (16 of 19) of the $P$. citricarpa isolates recovered from ascospore inoculations of Troyer seedlings were recombinant genotypes, while the remaining $16 \%$ of the population could not be distinguished from parental genotypes based on the four markers used. Three of four tested isolates from ascospore-derived fruit lesions were also recombinants.

\section{Discussion}

In this study, we fulfilled Koch's postulates for $P$. citricarpa ascospores and demonstrated the usefulness of Troyer seedlings as a model host susceptible to citrus black spot. Citrus black spot symptoms were successfully produced on leaves of Troyer and fruit of Murcott by inoculating them with characterized and standardized inoculum of $P$. citricarpa ascospores. In addition, $P$. citricarpa isolates were readily recovered from the symptomatic tissues and recombinant genotypes were identified among these isolates, confirming the hypothesis that black spot symptoms arising from ascospore inoculations were caused by the sexual spores. By reproducing citrus black spot symptoms, recovering the pathogen, and identifying recombinant genotypes from the ascospore inoculations, the present study has fulfilled Koch's postulates for ascospores of the citrus black spot pathogen. To our knowledge, this is the first time pathogenicity of pure ascospores produced from characterized $P$. citricarpa isolates has been confirmed, providing evidence for their ability to directly infect and cause disease on citrus leaves and fruit.

The demonstration that Troyer seedlings are susceptible to both conidia and ascospores of $P$. citricarpa, and produce symptoms after a latent period at least 2 months shorter than on fruit, presents new opportunities for studying the infection biology of $P$. citricarpa. Inoculation of Troyer seedlings offers advantages that overcome several of the challenges of using attached fruit. First, citrus black spot symptoms are produced within just 3 months after inoculation, making it more time efficient than fruit inoculations. We noticed one case in which an inoculated Troyer seedling subjected to drought stress expressed classic hard spot symptoms within a much shorter time of just 52 days after inoculation (data not shown). This observation warrants further investigation to determine the conditions affecting symptom expression, which may further improve time efficiency. Second, small seedlings (approximately $60 \mathrm{~cm}$ in height) are better suited to controlled-environment studies whereas working on attached fruit requires large fruiting trees (e.g., $2.5 \mathrm{~m}$ high in 3 to 5 years

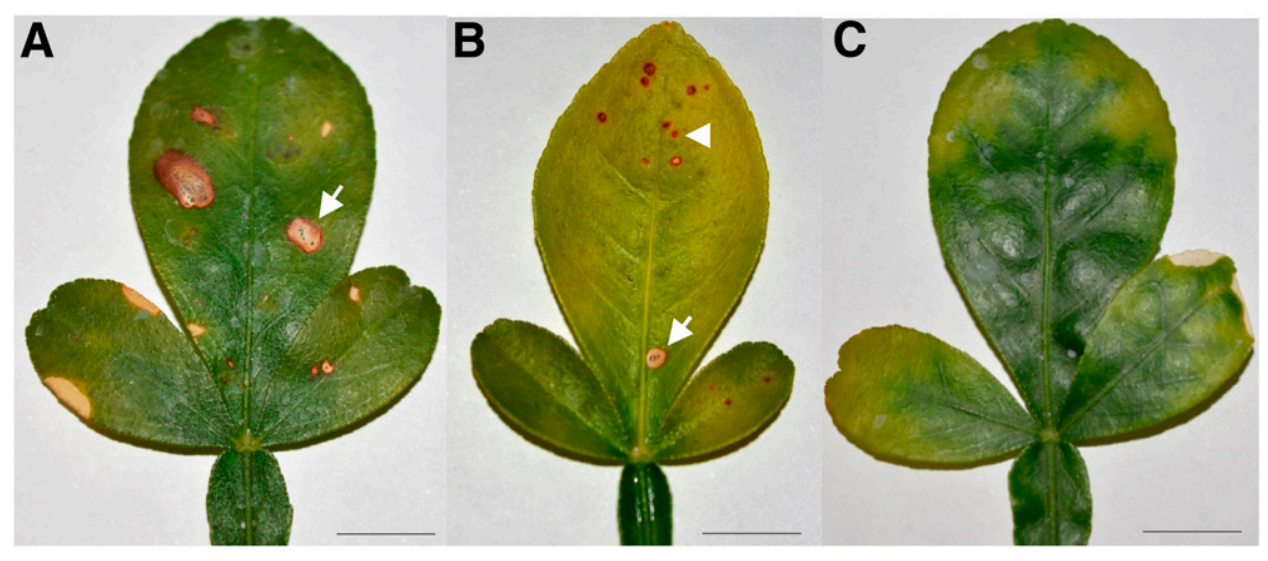

Fig. 1. Symptoms expressed by Troyer citrange (Citrus sinensis $\times$ Poncirus trifoliata) leaves inoculated with Phyllosticta citricarpa A, ascospores and B, conidia showing hard spot with pycnidia formed (arrows) and freckle spot (arrowhead); and C, asymptomatic negative control leaf treated with $0.02 \%$ Tween 20 at 4 months after inoculation. Scale bar = $10 \mathrm{~mm}$. 
A

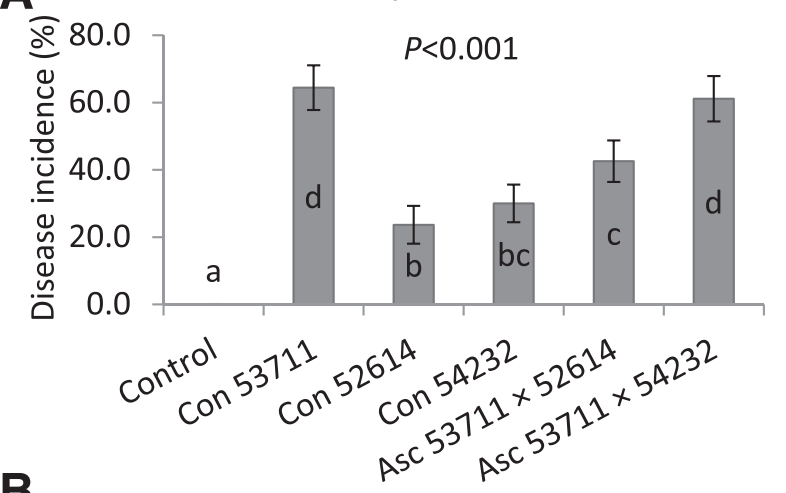

B

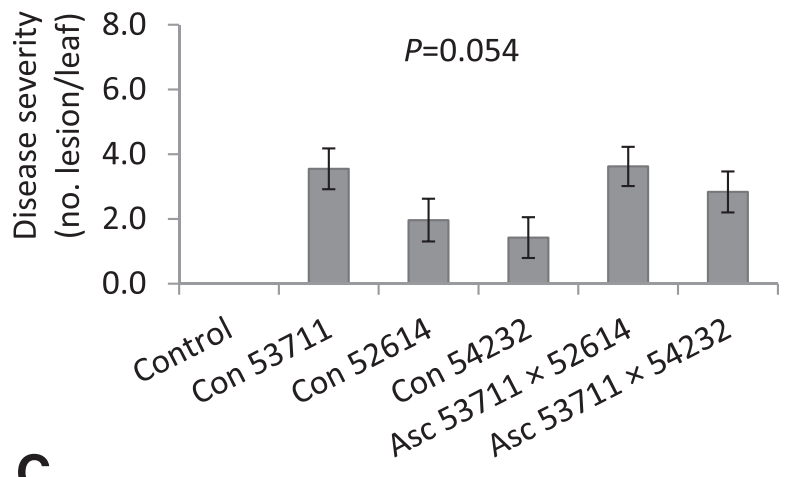

C
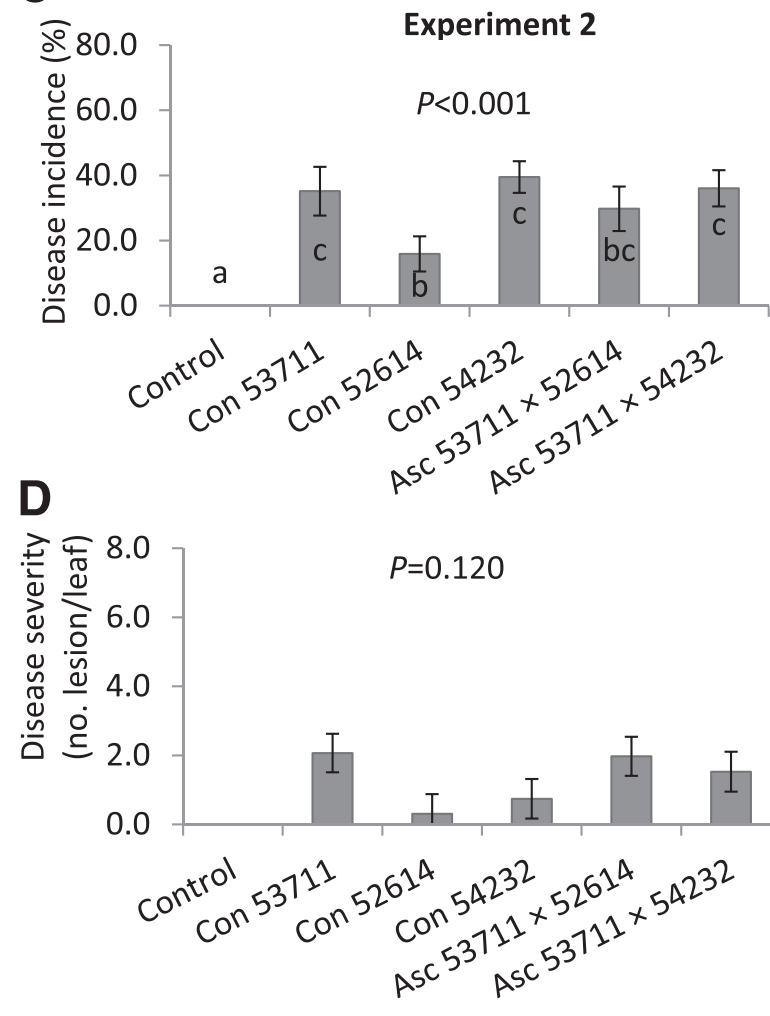

Inoculum source

Fig. 2. Citrus black spot incidence and severity on Troyer citrange (Citrus sinensis $\times$ Poncirus trifoliata) seedlings assessed at 4 months after inoculation with different sources of Phyllosticta citricarpa inoculum at A and B, $1 \times 10^{5}$ and C and D, $5 \times$ $10^{4}$ spores $/ \mathrm{ml}$. For each source of inoculum, data were combined across all leaf developmental stages. Different letters indicate a significant difference using Fisher's least significant difference test $(P<0.05)$. Bars $=$ standard errors, Control $=$ $0.02 \%$ Tween 20 , Con $=$ conidia, and Asc $=$ ascospores. Numbers following spore types are accessions of $P$. citricarpa isolates retrieved from the Queensland Plant Pathology Herbarium, Brisbane, Australia (BRIP).

\section{A Experiment 1}
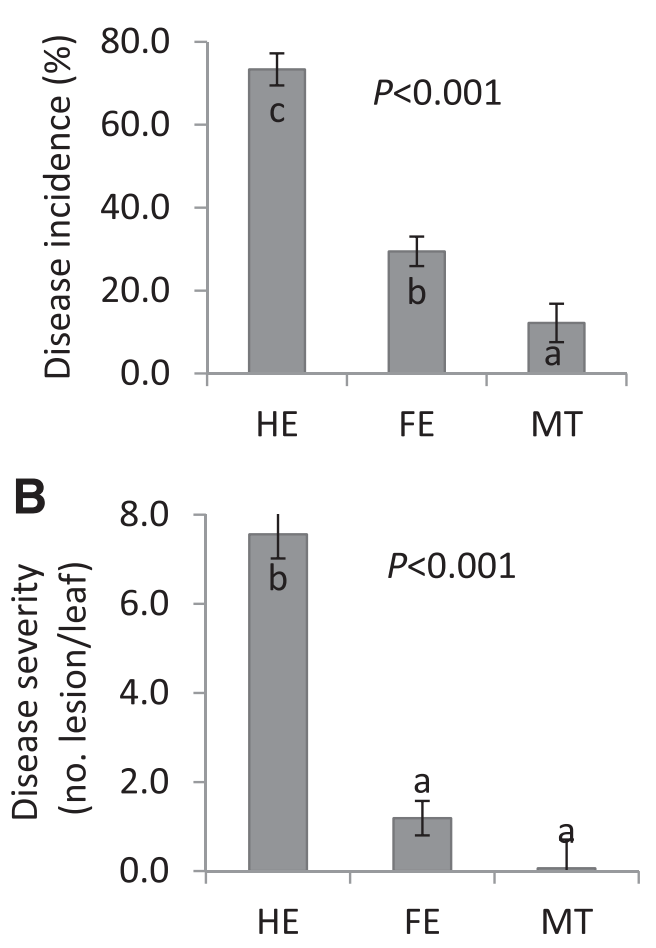

C Experiment 2
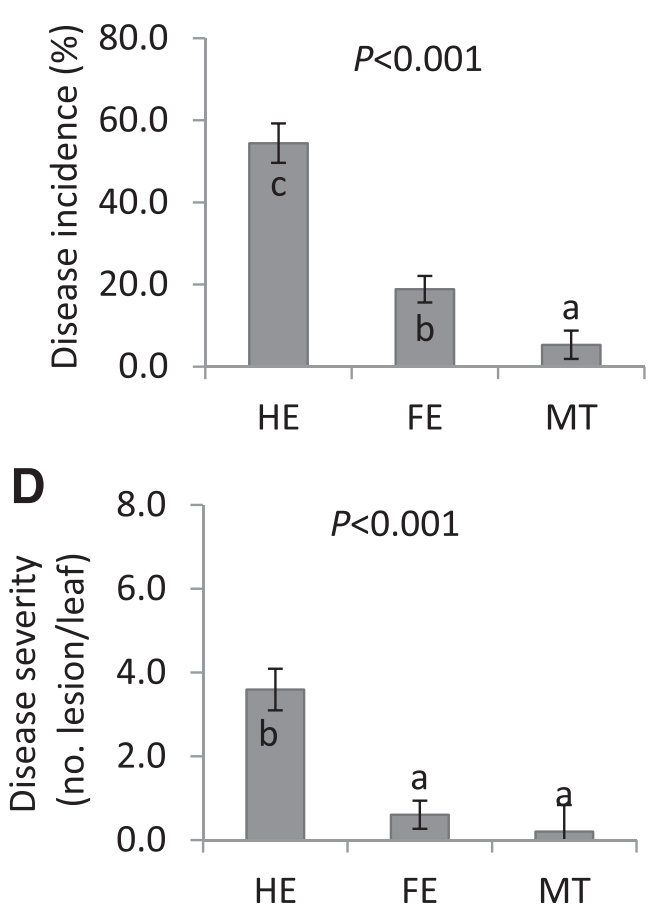

Leaf developmental stages

Fig. 3. Citrus black spot incidence and severity for different leaf developmental stages of Troyer citrange (Citrus sinensis $\times$ Poncirus trifoliata) seedlings assessed at 4 months after inoculation with the combined different sources of Phyllosticta citricarpa inoculum at A and B, $1 \times 10^{5}$ and C and D, $5 \times 10^{4}$ spores $/ \mathrm{ml}$. Different letters indicate a significant difference using Fisher's least significant difference test $(P<0.05)$. Bars $=$ standard errors, $\mathrm{HE}=$ halfexpanded soft leaves, $F E=$ fully expanded soft leaves, and MT= fully mature leaves. 
under optimal conditions) (Wheaton et al. 1991) that can be difficult to accommodate and manage. We also faced another challenge in our attached-fruit inoculations that a number of fruit dropped early, which may have prevented the symptoms from developing further, resulting in the atypical lesions (e.g., no pycnidia observed) (Fig. 4). Third, new growth flushes can be easily induced on seedlings at any time of year, whereas most Citrus spp. typically produce fruit only once per season. Fourth, the simple inoculation technique of applying a spore suspension onto young leaves has been shown to be reliable and efficient.

Pathogenicity on Troyer leaves may reflect the pathogenicity of $P$. citricarpa isolates to citrus fruit. This is evident from ascospores of the cross BRIP $53711 \times 54232$ being able to cause disease on both Troyer leaves and Murcott fruit. In addition, the ex-epitype isolate BRIP 52614, which readily produced citrus black spot symptoms on Troyer leaves in our study, was used by Miles et al. (2016) in their inoculations, where it consistently produced classic citrus black spot symptoms on fruit of various Citrus accessions. Therefore, the discovery that Troyer seedlings rapidly develop citrus black spot symptoms in response to $P$. citricarpa infection should provide a significant aid in future research, including determining environmental conditions

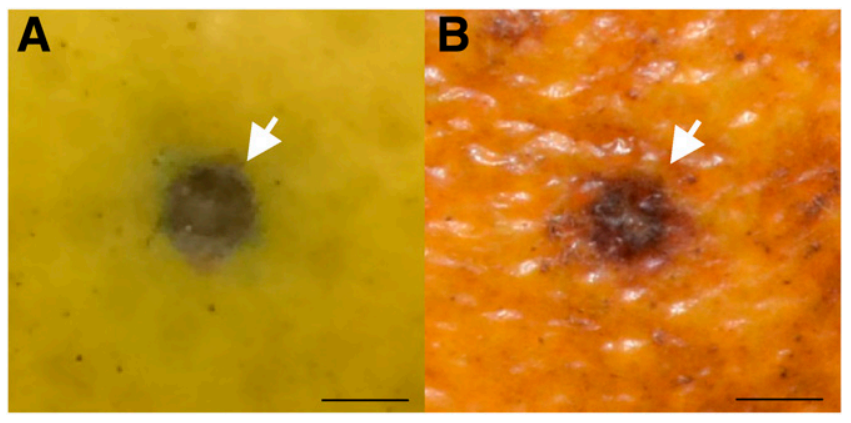

Fig. 4. Citrus black spot symptoms (arrows) resembling A, hard spot with sunken center and dark margin, and B, depressed freckle spot expressed on Murcott tangor (Citrus reticulata $\times$ C. sinensis) fruit inoculated with Phyllosticta citricarpa ascospores at 5 months after inoculation. Scale bar $=10 \mathrm{~mm}$. for infection. It may also create an opportunity to develop a screening technique to identify disease resistance at an early stage in citrus breeding programs (Smith et al. 2016).

We attempted to compare the role of ascospores and conidia in citrus black spot epidemiology through comparing the disease incidence and severity caused by each on Troyer seedlings. We found that conidia of all isolates and ascospores of the crosses were pathogenic. However, disease incidence and severity varied among conidia of different genotypes and ascospores of different crosses. For each mating cross, disease incidence and severity caused by the ascospores was within the range caused by conidia from the parental genotypes. In fungal plant diseases caused by pathogens that can undergo both asexual and sexual reproduction, it is important to understand the epidemiological role of each spore type (McDonald and Linde 2002). For example, in Fusarium head blight and crown rot of wheat caused by Fusarium spp., Mitter et al. (2006) found that ascospores were less effective than conidia in causing the diseases when the virulence of the two spore types were compared. In the case of light leaf spot (Pyrenopeziza brassicae) of winter oilseed rape, ascospores caused higher levels of infection on the leaves than conidia (Gilles et al. 2001). In the present study, although disease incidence and severity caused by ascospores was neither more or less than that caused by conidia of the two corresponding parental isolates, genotypic and phenotypic variability among isolates recovered from ascospores requires broader-scale assessment. Our experiments provide evidence that different genotypes of Phyllosticta citricarpa isolates may vary in their aggressiveness, as shown by the differences in disease incidence between conidial inocula produced from parental isolates BRIP 53711, 52614, and 54232. Therefore, future studies to confirm the relative aggressiveness of ascospores and conidia will need to include conidial inoculum derived from ascospore isolates to account for the genetic variability arising from sexual reproduction. Furthermore, studies of the epidemiological significance of asexual and sexual spores will need to consider the influence of genetic diversity on pathogenicity, as well as the factors of fecundity, viability, and dispersal.

Although citrus black spot is regarded as both a fruit and foliar disease, disease symptoms are mostly observed on fruit unless trees are

Table 1. Genotypes of Phyllosticta citricarpa isolates recovered from citrus black spot symptoms arising from inoculation of Troyer citrange (Citrus sinensis $\times$ Poncirus trifoliata) leaves and Murcott tangor $($ C. reticulata $\times$ C. sinensis $)$ fruit with ascospores and conidia

\begin{tabular}{|c|c|c|c|c|c|c|}
\hline \multirow[b]{2}{*}{ Isolate details } & \multirow[b]{2}{*}{$N^{\mathrm{a}}$} & \multirow[b]{2}{*}{$\mathbf{M T}^{\mathbf{b}, \mathbf{c}}$} & \multicolumn{3}{|c|}{ Simple sequence repeat loci examined } & \multirow[b]{2}{*}{ Genotypes } \\
\hline & & & $6(\mathrm{CAA})^{\mathrm{c}}$ & $12(\mathrm{ACC})^{\mathrm{c}}$ & $\overline{\operatorname{Pc117}(\text { GATT) }}{ }^{\mathrm{d}}$ & \\
\hline BRIP 53711e & $\ldots$ & MAT1-1 & 8 & 14 & 18 & Parent 1 \\
\hline BRIP 54232e & $\ldots$ & MAT1-2 & 12 & 11 & 27 & Parent 2 \\
\hline \multicolumn{7}{|l|}{ Leaf inoculations ${ }^{\mathrm{f}}$} \\
\hline BRIP 53711 (con) & 7 & MAT1-1 & 8 & 14 & 18 & Parent 1 \\
\hline BRIP 54232 (con) & 6 & MAT1-2 & 12 & 11 & 27 & Parent 2 \\
\hline \multirow[t]{11}{*}{ BRIP $53711 \times 54232$ (asc) } & 2 & MAT1-1 & 8 & 14 & 18 & Parent 1 \\
\hline & 1 & MAT1-2 & 12 & 11 & 27 & Parent 2 \\
\hline & 3 & MAT1-2 & 8 & 14 & 18 & Hybrid 1 \\
\hline & 1 & $M A T 1-2$ & 8 & 11 & 18 & Hybrid 2 \\
\hline & 2 & MAT1-1 & 12 & 14 & 18 & Hybrid 3 \\
\hline & 1 & MAT1-1 & 12 & 11 & 18 & Hybrid 4 \\
\hline & 3 & MAT1-1 & 8 & 11 & 18 & Hybrid 5 \\
\hline & 2 & MAT1-1 & 12 & 11 & 27 & Hybrid 6 \\
\hline & 1 & MAT1-2 & 12 & 14 & 18 & Hybrid 7 \\
\hline & 1 & $M A T 1-2$ & 12 & 11 & 18 & Hybrid 8 \\
\hline & 2 & MAT1-2 & 8 & 14 & 27 & Hybrid 9 \\
\hline \multicolumn{7}{|l|}{ Fruit inoculations ${ }^{\mathrm{f}}$} \\
\hline \multirow[t]{3}{*}{ BRIP $53711 \times 54232$ (asc) } & 1 & MAT1-1 & 8 & 14 & 18 & Parent 1 \\
\hline & 2 & MAT1-1 & 12 & 11 & 18 & Hybrid 4 \\
\hline & 1 & MAT1-2 & 8 & 14 & 27 & Hybrid 9 \\
\hline
\end{tabular}

\footnotetext{
a Number of isolates.

${ }^{\mathrm{b}} \mathrm{MT}=$ mating type.

c Primers published by Wang et al. (2016).

d Primers published by Carstens et al. (2017).

e Parental isolates retrieved from Queensland Plant Pathology Herbarium, Brisbane, Australia (BRIP) and characterized by Miles et al. (2013).

${ }^{\mathrm{f}}$ Recovered after inoculation with conidia (con) or ascospores (asc).
} 
under stress or leaves are senescent (Baldassari et al. 2008; Kotzé 1981). However, in our study, citrus black spot symptoms were readily produced on leaves of Troyer seedlings. We found a significant correlation between leaf developmental stage and disease incidence and severity, in that inoculation of younger leaves resulted in more prevalent and severe disease expression. In addition, symptoms on young leaves (i.e., half-expanded and fully expanded soft leaves) were more typical of citrus black spot (i.e., hard spot and freckle spot containing pycnidia in the lesion center) whereas symptoms produced on mature leaves did not contain pycnidia. This finding is similar to what has been reported with citrus fruit, in that infection by $P$. citricarpa only takes place when fruit are young (up to 24 weeks old from fruit set) (Baldassari et al. 2006; Spósito et al. 2007; Spósito et al. 2011). The reasons for these changes in susceptibility of citrus tissues to $P$. citricarpa or effects of environmental conditions on infection are not well understood. Therefore, systematic inoculation studies to better define the susceptible period of citrus tissues and conditions favoring infection and symptom development and expression would be helpful in making disease control decisions.

Despite the fact that citrus black spot was officially described over a century ago (Benson 1895), little progress has been made in understanding the epidemiology of sexual spores and the contribution of the sexual cycle to disease epidemics. By fulfilling Koch's postulates for $P$. citricarpa ascospores, the present study has provided firm evidence that ascospores can directly infect and cause disease on leaves of Troyer seedlings and fruit of Murcott tangor. Furthermore, by identifying Troyer seedlings as a model system for inoculation experiments, this study may facilitate future research to address many of the unanswered questions concerning citrus black spot. In particular, Troyer seedlings provide an opportunity for in planta studies of the environmental conditions necessary for infection which, to date, have relied on extrapolation from in vitro modeling studies or studies of other fungi (Fourie et al. 2013; Whiteside 1974; Yonow et al. 2013). Improved knowledge of epidemiological aspects of $P$. citricarpa ascospores and impacts of sexual reproduction on pathogenicity and disease epidemiology will facilitate the development of better disease management and containment strategies, and may ultimately reduce losses caused by citrus black spot.

\section{Acknowledgments}

We thank T. A. Shuey for technical support, S. Mudge for critically reviewing the manuscript and photography, and $\mathrm{K}$. Chandra for helping with data analysis.

\section{Literature Cited}

Amorim, R., Savi, D. C., Ferreira-Maba, L., Aluizio, R., Goulin, E. H., Takita, M. A., Machado, M. A., and Glienke, C. 2017. MAT gene idiomorphs suggest a heterothallic sexual cycle in the citrus pathogen Phyllosticta citricarpa. Eur. J. Plant Pathol. 147:325-337.

Baayen, R. P., Bonants, P. J. M., Verkley, G., Carroll, G. C., van der Aa, H. A., de Weerdt, M., van Brouwershaven, I. R., Schutte, G. C., Maccheroni, W., de Blanco, C. G., and Azevedo, J. L. 2002. Nonpathogenic isolates of the citrus black spot fungus, Guignardia citricarpa, identified as a cosmopolitan endophyte of woody plants, G. mangiferae (Phyllosticta capitalensis). Phytopathology 92:464-477

Baker, K. F. 1957. The U.C. System for Producing Healthy Container-Grown Plants. University of California, Division of Agricultural Sciences, Agricultural Experiment Station, Extension Service, Berkeley.

Baldassari, R. B., Reis, R. F., and Goes, A. D. 2006. Susceptibility of fruits of the 'Valencia' and 'Natal' sweet orange varieties to Guignardia citricarpa and the influence of the coexistence of healthy and symptomatic fruits. Fitopatol. Bras. 31:337-341.

Baldassari, R. B., Reis, R. F., and Goes, A. D. 2009. A new method for inoculation of fruit with Guignardia citricarpa, the causal agent of citrus black spot. Eur. J. Plant Pathol. 123:1-4.

Baldassari, R. B., Wickert, E., and de Goes, A. 2008. Pathogenicity, colony morphology and diversity of isolates of Guignardia citricarpa and G. mangiferae isolated from Citrus spp. Eur. J. Plant Pathol. 120:103-110.

Benson, A. H. 1895. Black spot of the orange. Agric. Gaz. N. S. W. 6:249-251.

Brentu, F. C., Oduro, K. A., Offei, S. K., Odamtten, G. T., Vicent, A., Peres, N. A., and Timmer, L. W. 2012. Crop loss, aetiology, and epidemiology of citrus black spot in Ghana. Eur. J. Plant Pathol. 133:657-670.

Brodrick, C. 1970. Light and temperature effects on symptom development and sporulation of Guignardia citricarpa Kiely, on Citrus sinensis (Linn.) Osbeck. Phytophylactica 2:157-164
Carstens, E., Linde, C., Slabbert, R., Miles, A., Donovan, N., Li, H.-Y., Zhang, K. Dewdney, M. M., Rollins, J. A., Glienke, C., Schutte, G. C., Fourie, P., and McLeod, A. 2017. A global perspective on the population structure and reproductive system of Phyllosticta citricarpa. Phytopathology 107:758-768.

Castle, W. S. 2010. A career perspective on citrus rootstocks, their development and commercialization. HortScience 45:11-15.

de Goes, A., Baldassari, R. B., Feichtenberger, E., Aguilar-Vildoso, C. I., and Spósito, M. B. 2000. Cracked spot, a new symptom of citrus black spot (Guignardia citricarpa). Pages 1001-1002 in: Brazil. Proc. Int. Congr. Citricult.

Fourie, P., Schutte, T., Serfontein, S., and Swart, F. 2013. Modeling the effect of temperature and wetness on Guignardia pseudothecium maturation and ascospore release in citrus orchards. Phytopathology 103:281-292.

Gilles, T., Fitt, B. D. L., McCartney, H. A., Papastamati, K., and Steed, J. M. 2001. The roles of ascospores and conidia of Pyrenopeziza brassicae in light leaf spot epidemics on winter oilseed rape (Brassica napus) in the UK. Ann. Appl. Biol. 138:141-152.

Glienke, C., Pereira, O. L., Stringari, D., Fabris, J., Kava-Cordeiro, V., GalliTerasawa, L., Cunnington, J., Shivas, R. G., Groenewald, J. Z., and Crous, P. W. 2011. Endophytic and pathogenic Phyllosticta species, with reference to those associated with citrus black spot. Persoonia 26:47-56.

Guarnaccia, V., Groenewald, J. Z., Li, H., Glienke, C., Carstens, E., Hattingh, V., Fourie, P. H., and Crous, P. W. 2017. First report of Phyllosticta citricarpa and description of two new species, $P$. paracapitalensis and $P$. paracitricarpa, from citrus in Europe. Stud. Mycol. 87:161-185.

Iglesias, D. J., Cercós, M., Colmenero-Flores, J. M., Naranjo, M. A., Ríos, G. Carrera, E., Ruiz-Rivero, O., Lliso, I., Morillon, R., and Tadeo, F. R. 2007. Physiology of citrus fruiting. Braz. J. Plant Physiol. 19:333-362.

Kiely, T. B. 1948. Preliminary studies on Guignardia citricarpa, N. SP.: The ascigerous stage of Phoma citricarpa McAlp., and its relation to black spot of citrus. Proc. Linn. Soc. N. S. W. 73:249-292.

Kotzé, J. 1981. Epidemiology and control of citrus black spot in South Africa Plant Dis. 65:945-950.

Marques, J. P. R., Spósito, M. B., Mello, A. F. S., Amorim, L., Mondin, M., and Appezzato-da-Glória, B. 2011. Histopathology of black spot symptoms in sweet oranges. Eur. J. Plant Pathol. 133:439-448.

McDonald, B. A., and Linde, C. 2002. Pathogen population genetics, evolutionary potential, and durable resistance. Annu. Rev. Phytopathol. 40:349-379.

McOnie, K. C. 1964a. Source of inoculum of Guignardia citricarpa, the citrus black spot pathogen. Phytopathology 54:64-67.

McOnie, K. C. 1964b. Orchard development and discharge of ascospores of Guignardia citricarpa and the onset of infection in relation to control of citrus black spot. Phytopathology 54:1448-1453.

McOnie, K. C. 1967. Germination and infection of citrus by ascospores of Guignardia citricarpa in relation to control of black spot. Phytopathology 57:743-746.

Miles, A. K., Smith, M. W., Tran, N. T., Shuey, T. A., Drenth, A., and Dewdney, M. M. 2016. Fruit inoculation studies with Phyllosticta citricarpa, the cause of citrus black spot. Page 132 in: 13th Int. Citrus Congr. Foz Do Iguacu, Brazil. D. J. Mattos, E. F. Carlos, V. M. Novelli, F. A. de Azevedo, H. D. C. Filho, and P. V. C. Zaccheo, eds.

Miles, A. K., Tan, Y. P., Tan, M. K., Donovan, N. J., Ghalayini, A., and Drenth, A 2013. Phyllosticta spp. on cultivated Citrus in Australia. Australas. Plant Pathol. 42:461-467.

Mitter, V., Francl, L. J., Ali, S., Simpfendorfer, S., and Chakraborty, S. 2006 Ascosporic and conidial inoculum of Gibberella zeae play different roles in Fusarium head blight and crown rot of wheat in Australia and the USA Australas. Plant Pathol. 35:441-452.

Moran Lemir, A. H., Stadnik, M. J., Buchenauer, H., and Canton, N. V. 2000. In vitro production of ascospores and pathogenicity of Guignardia citricarpa, causal agent of citrus black spot. Summa Phytopathol. 26:374-376.

Schubert, T. S., Dewdney, M. M., Peres, N. A., Palm, M. E., Jeyaprakash, A., Sutton, B., Mondal, S. N., Wang, N.-Y., Rascoe, J., and Picton, D. D 2012. First report of Guignardia citricarpa associated with citrus black spot on sweet orange (Citrus sinensis) in North America. Plant Dis. 96: 1225 .

Smith, M. W., Gultzow, D. L., Newman, T. K., Parfitt, S. C., and Miles, A. K. 2016. A co-inoculation technique to rapidly screen citrus hybrids for resistance to both Alternaria brown spot caused by Alternaria alternata and citrus scab caused by Elsinoë fawcettii. Citrus Res. Technol. 37:83-87.

Spósito, M. B., Amorim, L., Bassanezi, R. B., and Hau, B. 2008. Spatial pattern of black spot incidence within citrus trees related to disease severity and pathogen dispersal. Plant Pathol. 57:103-108.

Spósito, M. B., Amorim, L., Bassanezi, R. B., Yamamoto, P. T., Felippe, M. R., and Czermainski, A. B. C. 2011. Relative importance of inoculum sources of Guignardia citricarpa on the citrus black spot epidemic in Brazil. Crop Prot. 30:1546-1552.

Spósito, M. B., Amorim, L., Ribeiro, P. J., Jr., Bassanezi, R. B., and Krainski, E. T. 2007. Spatial pattern of trees affected by black spot in citrus groves in Brazil. Plant Dis. 91:36-40.

Tran, N. T., Miles, A. K., Dietzgen, R. G., Dewdney, M. M., Zhang, K., Rollins, J. A., and Drenth, A. 2017. Sexual reproduction in the citrus black spo pathogen, Phyllosticta citricarpa. Phytopathology 107:732-739. 
Truter, M., Labuschagne, P. M., Kotzé, J. M., Meyer, L., and Korsten, L. 2007. Failure of Phyllosticta citricarpa pycnidiospores to infect Eureka lemon leaf litter. Australas. Plant Pathol. 36:87-93.

Wang, N.-Y., Zhang, K., Huguet-Tapia, J. C., Rollins, J. A., and Dewdney, M. M. 2016. Mating type and simple sequence repeat markers indicate a clonal population of Phyllosticta citricarpa in Florida. Phytopathology 106: 1300-1310.

Wang, X., Chen, G., Huang, F., Zhang, J., Hyde, K. D., and Li, H. 2012. Phyllosticta species associated with citrus diseases in China. Fungal Divers. 52:209-224.

Wheaton, T. A., Castle, W. S., Whitney, J. D., and Tucker, D. P. H. 1991. Performance of citrus scion cultivars and rootstock in a high-density planting. HortScience 26:837-840.
Whiteside, J. O. 1974. Environmental factors affecting infection of citrus leaves by Mycosphaerella citri. Phytopathology 64:115-120.

Wikee, S., Lombard, L., Crous, P. W., Nakashima, C., Motohashi, K. Chukeatirote, E., Alias, S. A., McKenzie, E. H. C., and Hyde, K. D. 2013. Phyllosticta capitalensis, a widespread endophyte of plants. Fungal Divers. 60:91-105.

Wulandari, N. F., To-Anun, C., Hyde, K. D., Duong, L. M., De Gruyter, J., Meffert, J. P., Groenewald, J. Z., and Crous, P. W. 2009. Phyllosticta citriasiana sp. nov., the cause of citrus tan spot of Citrus maxima in Asia. Fungal Divers. 34: 23-39.

Yonow, T., Hattingh, V., and de Villiers, M. 2013. CLIMEX modelling of the potential global distribution of the citrus black spot disease caused by Guignardia citricarpa and the risk posed to Europe. Crop Prot. 44:18-28. 